Published in final edited form as:

Sex Transm Dis. 2006 October ; 33(10): 604-609. doi:10.1097/01.olq.0000216029.00424.ae.

\title{
Correlates of Syphilis Seroreactivity Among Pregnant Women: The HIVNET 024 Trial in Malawi, Tanzania, and Zambia
}

\author{
Dara Potter, MBA ${ }^{\star}, \dagger$, Robert L. Goldenberg, $\mathrm{MD}^{\star}, \dagger$, Jennifer S. Read, MD, MPH ${ }^{\ddagger}$, Jing Wang,

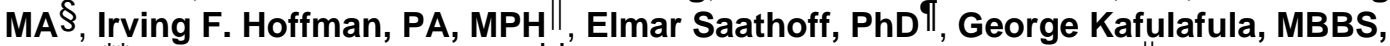 \\ MMed ${ }^{\star \star}$, Said Aboud, MD, MMed ${ }^{\dagger}$, Francis E. A. Martinson, MD, PhD\|, Maysoon Dahab, \\ MHS $\ddagger \ddagger$, and Sten H. Vermund, MD, PHD ${ }^{\star}, \S \S$
}

\begin{abstract}
"Schools of Public Health and Medicine, University of Alabama at Birmingham, Birmingham, Alabama ${ }^{\dagger}$ Centre for Infectious Disease Research in Zambia, Lusaka, Zambia ¥Pediatric, Adolescent, and Maternal AIDS Branch, National Institute of Child Health and Development, National Institutes of Health, Bethesda, Maryland §Statistical Center for HIV/AIDS Research \& Prevention, FHCRC, Seattle, Washington "University of North Carolina, Chapel Hill, North Carolina, and the UNC Project, Lilongwe, Malawi "Harvard School of Public Health, Boston, Massachusetts ${ }^{* *}$ College of Medicine, University of Malawi, Blantyre, Malawi ${ }^{\dagger+}$ Muhimbili University College of Health Sciences, Dar es Salaam, Tanzania 抽ohns Hopkins College of Medicine Research Project, Blantyre, Malawi $§ \S$ Vanderbilt University School of Medicine, Nashville, Tennessee
\end{abstract}

\section{Abstract}

\begin{abstract}
Objective-The objectives of this cross-sectional study were to determine correlates of syphilis seroprevalence among HIV-infected and -uninfected antenatal attendees in an African multisite clinical trial, and to improve strategies for maternal syphilis prevention.
\end{abstract}

\begin{abstract}
Results-A total of 2270 (86\%) women were HIV-infected and 366 (14\%) were HIV-uninfected. One hundred seventy-five (6.6\%) were syphilis-seropositive (7.3\% among HIV-infected and $2.6 \%$ HIV-uninfected women). Statistically significant correlates included geographic site (odds ratio [OR]
\end{abstract}

Copyright (C) 2006, American Sexually Transmitted Diseases Association All rights reserved.

Correspondence: Dara Potter, MBA, Centre for Infectious Disease Research in Zambia, Box 34681, 5977 Benekale \& Mwembeshi Roads, Northmead, Lusaka, Zambia. E-mail: dara@cidrz.org.

HIVNET 024 Team: Protocol Cochairs: Taha E. Taha, MD, PhD (Johns Hopkins University Bloomberg School of Public Health); Robert Goldenberg,MD (University of Alabama at Birmingham); In-Country Cochairs/Investigators of Record: Newton Kumwenda, PhD, George Kafulafula, MBBS, FCOG (Blantyre, Malawi); Francis Martinson, MD, PhD (Lilongwe, Malawi); Gernard Msamanga, MD, ScD (Dar es Salaam, Tanzania); Moses Sinkala, MD, MPH (Lusaka, Zambia); US Cochairs: Irving Hoffman, PA, MPH (University of North Carolina, Chapel Hill); Wafaie Fawzi, MD, DrPH (Harvard School of Public Health); In-Country Investigators, Consultants, and Key Site Personnel: Robin Broadhead, MBBS, FRCP, George Liomba, MBBS, FRCPath, Johnstone Kumwenda, MBChB, MRCP, Tsedal Mebrahtu, ScM, Pauline Katunda, MHS, Maysoon Dahab, MHS (Blantyre, Malawi); Peter Kazembe, MBChB, David Chilongozi CO, MPH, Charles Chasela, CO, MPH, George Joaki, MD, Willard Dzinyemba, Sam Kamanga (Lilongwe, Malawi); Elgius Lyamuya, MD, PhD, Charles Kilewo, MD, MMed, Karim Manji, MD, MMed, Sylvia Kaaya, MD, MS, Said Aboud, MD, MMed, Muhsin Sheriff, MD, MPH, Elmar Saathoff, PhD, Priya Satow, MPH, Illuminata Ballonzi, SRN, Gretchen Antelman, ScD, Edgar Basheka, BPharm (Dar es Salaam, Tanzania); Victor Mudenda, MD, Christine Kaseba, MD, Maureen Njobvu, MD, Makungu Kabaso, MD, Muzala Kapina, MD, Anthony Yeta, MD, Seraphine Kaminsa, MD, MPH, Constantine Malama, MD, Dara Potter, MBA, Maclean Ukwimi, RN, Alison Taylor, BSc, Patrick Chipaila, MSc, Bernice Mwale, BPharm (Lusaka, Zambia); U.S. Investigators, Consultants, and Key Site

Personnel: Priya Joshi, BS, Ada Cachafeiro, BS, Shermalyn Greene, PhD, Marker Turner, BS, Melissa Kerkau, BS, Paul Alabanza, BS, Amy James, BS, Som Siharath, BS, Tiffany Tribull, MS (UNC-CH); Saidi Kapiga, MD, ScD, George Seage, PhD (HSPH); Sten Vermund, MD, PhD, William Andrews, PhD, MD, Deedee Lyon, BS, MT(ASCP), Jeffrey Stringer, MD (UAB); NIAID Medical Officer: Samuel Adeniyi-Jones, MD; NICHD Medical Officer: Jennifer S. Read, MD, MS, MPH, DTM\&H; NIAID Protocol Pharmacist: Scharla Estep, RPh, MS; Protocol Statisticians: Elizabeth R. Brown, ScD, Thomas R. Fleming, PhD, Anthony Mwatha, MS, Lei Wang, PhD, Ying Q. Chen, $\mathrm{PhD}$ (University of Washington and Fred Hutchinson Cancer Research Center [FHCRC]); Protocol Virologist: Susan Fiscus, PhD (UNC-CH); Protocol Operations Coordinator: Lynda Emel, PhD (Statistical Center for HIV/AIDS Prevention [SCHARP], FHCRC); Data Coordinators: Debra J. Lands, EdM, Ceceilia J. Dominique; Systems Analyst Programmers: Alice H. Fisher, BA, Martha Doyle (SCHARP, FHCRC); Protocol Specialist: Megan Valentine, PA-C, MS (Family Health International). 
$=4.5$, Blantyre; $\mathrm{OR}=3.2$, Lilongwe; OR = 9.0, Lusaka vs. Dar es Salaam referent); HIV infection $(\mathrm{OR}=3.3)$; age 20 to 24 years $(\mathrm{OR}=2.5)$; being divorced, widowed, or separated $(\mathrm{OR}=2.9)$; genital ulcer treatment in the last year $(\mathrm{OR}=2.9)$; history of stillbirth $(\mathrm{OR}=2.8$, one stillbirth; $\mathrm{OR}=4.3$, $2-5$ stillbirths); and history of preterm delivery ( $\mathrm{OR}=2.7$, one preterm delivery).

Conclusion-Many women without identified risk factors were syphilis-seropositive. Younger HIV-infected women were at highest risk. Universal integrated antenatal HIV and syphilis screening and treatment is essential in sub-Saharan African settings.

Syphilis is a serious cause of maternal and infant morbidity and mortality. ${ }^{1-5}$ Syphilis during pregnancy is associated with stillbirth, spontaneous abortion, preterm birth, and intrauterine growth restriction. ${ }^{6}$ A Treponema pallidum-infected newborn may exhibit hepatosplenomegaly, failure to thrive, and high neonatal mortality. ${ }^{5,7-9}$ In addition to these serious reproductive outcomes, syphilis is a well-documented cofactor for horizontal (sexual), 10-12 as well as vertical (mother to child), transmission of HIV. ${ }^{10,13,14}$ In sub-Saharan Africa and elsewhere, syphilis and HIV serve as synergistic infections, each exacerbating the transmission of the other. ${ }^{15,16}$

Women in resource-limited settings may not receive routine screening for syphilis in antenatal care, and even if they are screened, treatment for infected mothers may be unavailable. ${ }^{7}$ In a chart review of 622 women receiving public sector antenatal care in Lusaka, Zambia, the rapid plasma reagin (RPR) assay was recorded in $81 \%$ of records, whereas only 2 of 44 positive results had treatment documented in their records at a time of penicillin supply shortages (1999-2000) (R. MacDonald and SHV, unpublished data; M. Sinkala, personal communication, May 2005).

Reported syphilis rates vary markedly between and within sub-Saharan African populations. Antenatal syphilis prevalence rates in Malawi, Tanzania, and Zambia are reported as $2.7 \%$ (year 2003; Venereal Diseases Reference Laboratory tests [VDRL], no confirmatory testing), ${ }^{17} 7.2 \%$ (year 2000; RPR confirmed with T. pallidum hemagglutination assay [TPHA]), ${ }^{18}$ and $8.2 \%$ (2001; RPR confirmed with TPHA), ${ }^{19}$ respectively. Regional seroprevalence differences may reflect a variety of sociocultural and economic factors, varying surveillance methods, and differential access to syphilis diagnosis and treatment. ${ }^{20}$ We examined demographic, sexual risk, and obstetric characteristics to predict syphilis sero-prevalence among HIV-infected and -uninfected antenatal attendees enrolled in a multisite clinical trial in Africa.

\section{Methods}

\section{Study Setting and Population}

The HIVNET 024 trial was a randomized, double-blind, placebo-controlled phase 3 clinical trial of antibiotics to prevent perinatal HIV transmission and preterm birth by reducing chorioamnionitis. ${ }^{21,22}$ The intervention studied in the trial was a relatively inexpensive $(<\$ 5$ US), 2-course antibiotic prophylactic regimen. Trial participants were recruited in 4 subSaharan African cities: Blantyre and Lilongwe, Malawi; Lusaka, Zambia; and Dar es Salaam, Tanzania. Enrollment started in July 2001 and was completed in February 2003. Consenting pregnant women were screened for HIV infection between 16 and 23 weeks gestation during an antenatal clinic visit before enrollment into the trial. Laboratory evaluations included HIV-1 serology screening by dual rapid test algorithm and Western blot confirmation of all positive or indeterminate results at 3 sites, whereas the Dar es Salaam site performed 2 enzyme-linked immunosorbent assays (ELISAs): Dade Behring Enzygnost anti-HIV-1/2 Plus(first ELISA) followed by Abbott Murex Wellcozyme anti-HIV-1 recombinant with discrepant results between the two ELISAs being confirmed by Western blot. Additional study laboratory evaluations included comprehensive screening for sexually transmitted infections (STIs) and 
complete blood counts. ${ }^{21}$ At 20 to 24 weeks gestational age, women were randomized to receive either $250 \mathrm{mg}$ metronidazole 3 times a day and $250 \mathrm{mg}$ erythromycin orally 3 times daily for 7 days or placebo for the control group. Participants were also given $250 \mathrm{mg}$ metronidazole and $500 \mathrm{mg}$ ampicillin (or placebo) at the 26- to 30-week visit to be taken at the onset of labor continuing after delivery 3 times daily until the 1-week course was completed. Five HIV-infected women were recruited for every one HIV-uninfected woman at the 2 Malawi and Zambian sites, whereas the Dar es Salaam site recruited only HIV-infected women as per the design of the parent trial. The primary study outcome was mother-to-child transmission of HIV, whereas secondary outcomes included other causes of morbidity and mortality such as preterm birth. Sociodemographic, living environment, obstetric, and sexual history data were collected at the study enrollment visit using a standardized structured questionnaire enabling the present nested study. Research nurses interviewed enrolled participants confidentially in private rooms. The study was approved by U.S. and in-country institutional ethical review boards or committees in each country. Written informed consent was obtained from all enrolled participants.

\section{Laboratory Procedures}

HIV testing was performed at a screening visit according to site-specific procedures using either conventional HIV ELISA tests or dual HIV rapid tests. These tests were validated by a central reference laboratory in the United States. HIV-infected women were offered motherto-child transmission prophylaxis with nevirapine. ${ }^{23,24}$ Women were tested for syphilis using RPR tests (Blantyre, Lilongwe, and Lusaka) or VDRL tests (Dar es Salaam) as part of preentry evaluations at the enrollment visit. Confirmation of the syphilis screening test was performed with the microhemagglutination T. pallidum test (MHA-TP) (Lilongwe), T. pallidum particle agglutination test (TPPA) (Dar es Salaam), or TPHA (Blantyre). Both TPPA and TPHA tests were used to confirm positive RPR samples from Lusaka. Women with a reactive syphilis test were treated with intramuscular benzathine penicillin at no cost.

\section{Statistical Analysis}

For purposes of this study, a confirmed test was used as the basis for syphilis diagnosis. Data obtained at the enrollment visit (20-24 weeks gestation) were used for this study. A woman was considered to have maternal syphilis if, at the time of HIVNET 024 enrollment, her serum was reactive according to one of the screening and one of the confirmatory tests. Higher socioeconomic status was estimated from data on availability of electricity or running water in the home.

Associations between syphilis serostatus and demographic, sexual history, or obstetric variables were assessed using odds ratios (ORs) and chi-square, Student t, or Fisher exact tests, as appropriate, to determine statistical significance. Multivariable logistic regression analysis was used to further investigate those associations that were significant at a $P<0.05$ (2-tailed) level with syphilis sero-prevalence in the bivariate analyses. Findings are presented as adjusted odds ratios $\left(\mathrm{OR}_{\mathrm{adj}}\right)$ with corresponding $95 \%$ confidence intervals $(95 \% \mathrm{CIs})$ and/or $P$ values. The logistic models were performed for the overall population of HIV-infected and -uninfected women and separately stratified by HIV infection status. All statistical analyses were performed with SAS version 9.1 (SAS, Inc., Cary, NC).

\section{Results}

\section{Study Population, Syphilis Seroprevalence}

Of 2661 women who gave informed consent for enrollment into HIVNET 024, 2636 (99\%) had a syphilis screening test and, if the screening test was positive, a confirmatory test. All 2636 of these women were included in this syphilis substudy. As per the study design, 2270 
(86\%) were HIV-infected and $366(14 \%)$ were HIV-uninfected. At enrollment, 175 (6.6\%) women were confirmed syphilis positive, $7.3 \%$ among HIV-infected and $2.5 \%$ among HIVuninfected $(\mathrm{OR}=3.1,95 \% \mathrm{CI}=1.6-6.2)$. Overall site-specific seroprevalence rates ranged from 1.4\% in Dar es Salaam, Tanzania, to $11.7 \%$ in Lusaka, Zambia. The rates were intermediate in Lilongwe (5.1\%) and Blantrye (6.3\%), Malawi (Table 1). Among the HIVinfected women, the site-specific syphilis seroprevalences were: 1.4\% in Dar es Salaam, 5.9\% in Lilongwe, $7.3 \%$ in Blantrye, and $13.0 \%$ in Lusaka. Among the HIV-uninfected women, the site-specific confirmed syphilis rates were: $1.1 \%$ in Blantyre, $1.4 \%$ in Lilongwe, and $4.9 \%$ in Lusaka.

\section{Sociodemographic Characteristics, Sexual and Obstetric History}

In bivariate analyses, women were more likely to be syphilis-seropositive if they came from the Malawi or Zambia sites, were HIV-infected, were 20 to 24 years old, had completed less than 6 years of formal education, were illiterate, were divorced/separated/widowed, were of lower socioeconomic status, had a greater number of lifetime sexual partners, had been treated for genital ulcers in the last year, had a greater number of past pregnancies, had a history of stillbirth, and a history of preterm delivery (Table 1).

In bivariate analyses, the following variables were not significant: years of formal education of spouse/partner, occupation, spouse/partner's occupation, housing type, use of gas/electrical or charcoal stove or firewood for cooking, number of lifetime sexual partners in the current pregnancy, condom use during the current pregnancy, having been treated for abnormal vaginal discharge in the last year, and number of abortions or miscarriages.

Women at each of the 4 sites were of similar age, education, literacy, marital status, and occupation, except that women in Dar es Salaam were of higher socioeconomic status as measured by electricity and running water on their premises and use of a paraffin stove or firewood for cooking. Results of site-specific analyses were very similar to the findings of the overall analysis (data not shown).

\section{Correlates of Syphilis Seroprevalence}

In the multivariable logistic regression analysis for the 4 sites combined, 7 factors were found to be independent and statistically significant correlates of syphilis seroprevalence among the antenatal attendees (Table 2): geographic site ( $\mathrm{OR}=4.5$, Blantyre; $\mathrm{OR}=3.2$, Lilongwe; $\mathrm{OR}$ = 9.0, Lusaka, vs. Dar es Salaam referent population), HIV infection $(\mathrm{OR}=3.3)$, maternal age 20 to 24 years ( $\mathrm{OR}=2.5$ vs. age $16-19$ years), being divorced/widowed/ separated $(\mathrm{OR}=2.9$ vs. married or living with partner), having had treatment for genital ulcers in the last year (OR $=2.9$ ), history of stillbirth ( $\mathrm{OR}=2.8$ for one stillbirth; $\mathrm{OR}=4.3$ for $2-5$ stillbirths $)$, or having had a preterm delivery ( $\mathrm{OR}=2.7$ for one preterm delivery).

The same variables were found significant in bivariate analyses for the HIV-infected women as for the combined cohort and were used in a multivariable analysis assessment. The multivariable logistic regression analysis results were similar for the combined HIV-infected and -uninfected cohort $(\mathrm{n}=2636)$ as for the HIV-infected cohort alone $(\mathrm{n}=2270)$ (results not shown for HIV-infected cohort). There were 9 syphilis-seropositive women among the HIVuninfected cohort of women $(\mathrm{n}=366)$. No variables were found to be independent and statistically significant correlates of syphilis seroreactivity among the HIV-uninfected women in multivariable analysis. 


\section{Discussion}

There were variations in syphilis seroprevalence among sites, with the Lusaka, Zambia, site having an especially high seroprevalence (11.7\%). Women with HIV infection were more likely to be syphilis-seropositive as were women who were divorced, separated, or widowed. Women with a history of stillbirth or preterm delivery were significantly more likely to be syphilis-seropositive, confirming the well-known reproductive health consequences of maternal and congenital syphilis. A surprising result was the significant association of syphilis among women in the 20- to 24-year age group as compared with older women. Typically, syphilis rates are highest in older women, but given $86 \%$ of women enrolled in the study were HIV-infected and the extremely limited access to antiretroviral therapy in the time period of the study, older women with syphilis and HIV may well have died before study commencement, distorting the age-risk associations. ${ }^{25}$ Although the number of sexual partners during the current pregnancy was not significantly associated with syphilis, the number of lifetime sexual partners was found to be statistically significant on bivariate and multivariable analyses, suggesting that syphilis risk is not specific to the time of pregnancy per se. ${ }^{10,26}$

Higher syphilis risk is documented in divorced and widowed women in Senegal, ${ }^{27}$ although single marital status was the risk factor noted in a previous Tanzania study. ${ }^{28}$ Previous studies related to pregnant women in developing countries reported the following risk factors for maternal syphilis, similar to our findings: HIV infection, ${ }^{29}$ history of stillbirth, ${ }^{30}$ history of preterm delivery, ${ }^{31}$ previous perinatal death, ${ }^{32}$ high-risk sexual behaviors, ${ }^{33}$ history of abortion, ${ }^{34}$ genital ulcer disease, ${ }^{35}$ and lower socioeconomic status. ${ }^{36}$ The economic indicators in this study (presence of water or electricity in the home) suggest that antenatal attendees in Dar es Salaam had a higher socioeconomic status, perhaps associated with lower sexual and syphilis risks. Higher socioeconomic status is associated with decreased syphilis seroreactivity. 33,37,38 A history of stillbirth was significantly associated with syphilis seroreactivity in our study; in southern Africa, up to half of all stillbirths are found in syphilis-seroreactive women, with $\leq 25 \%$ of all stillbirths being attributed to syphilis. ${ }^{39}$

In a study of 1058 HIV-infected women in Dar es Salaam, Tanzania (2001), antenatal attendees, independent risk factors for syphilis seroreactivity (positive on both VDRL and TPHA) were: age 20 to 24 years and 30 to 34 years (compared with women 15-19 years old), abnormal vaginal discharge in the past year, a genital ulcer on examination, or current Trichomonas vaginalis infection. ${ }^{40}$ Women who were fully supported by their male partners were at a reduced risk of active syphilis compared with those with their own personal income source. ${ }^{40}$

Inefficient and ineffective antenatal syphilis screening programs in developing countries are well documented. ${ }^{7,41-44}$ Although each of the women enrolled in this study was screened for syphilis and, if reactive, treated, we do not know the coverage rates of the antenatal syphilis screening programs in these 4 sites for nonresearch patients. In Zambia and Malawi, in particular, high seroprevalence rates suggest the need to improve syphilis screening and treatment in concert with other essential antenatal services. ${ }^{45}$ Advocacy by developing country governments and international economic and/or technical assistance is needed to support strapped health workers and systems to achieve a long-term goal of sustainability.

Our seroprevalence findings are a legitimate comparison between 4 African cities, but they might not reflect background syphilis seroprevalence because: 1) $86 \%$ of the women were HIV-infected as a result of the design of the parent clinical trial; 2) antenatal attendees who consented to join the research study may have been more likely to have had STIs or history of obstetric complication than other women; and 3) recruitment for the study occurred among women already in the antenatal care system; thus, women who joined the study were those who "booked early" because enrollment only occurred from 20 to 24 weeks gestation. These 
selection factors indicate that our study seroprevalence is not generalizable; higher syphilis seroprevalence might be expected from HIV-infected women; lower rates might be seen in women booking relatively early (20-24 weeks gestation) for antenatal care; higher rates might be seen in women booking early as a result of reproductive tract symptoms; and lower rates might be seen in women seeking care through research-related programs because they potentially perceived it of higher quality than the government care system. We did not find the higher syphilis rates among HIV-infected women in the lower HIV prevalence nation; the lowest syphilis rates were noted in Tanzania where HIV prevalence is lower than in Malawi or Zambia. ${ }^{46,47}$

Antenatal syphilis screening programs must be evaluated for effectiveness and reformed accordingly. Infants receiving antiretroviral prophylaxis as part of a prevention of mother-tochild HIV transmission (PMTCT) program have been documented to die of congenital syphilis in a program in which syphilis screening had not been a part of HIV prevention activities. ${ }^{48}$ Vertical integration of syphilis screening in antenatal HIV prevention programs is a way to strengthen existing health systems and to improve on health outcomes, particularly in resourcelimited settings where obstacles to universal antenatal screening may abound ${ }^{48}$ analogous to joint HIV and tuberculosis screening that is advocated in high-prevalence regions. ${ }^{49} \mathrm{~A}$ routine, universal, "opt-out" approach to joint syphilis and HIV screening would improve coverage and care for both. ${ }^{50}$ In Lilongwe, Malawi, for example, where a mature PMTCT program has resulted in almost universal acceptance of voluntary counseling and testing (VCT) based on fingerstick, whole-blood HIV rapid testing, a pilot program is being conducted to routinely perform syphilis rapid tests (and treatment) during the VCT session. ${ }^{51}$ Given the high rates of HIV and syphilis coinfection, antenatal care providers may consider an antenatal attendee's marital status and age; if resources are scarce and must be prioritized, those attendees who are younger, divorced, widowed, or separated are likely to be at higher risk for both infectious diseases. Although recognition of syphilis risk factors is useful, many women without the risk factor characteristics were syphilis-seroreactive; universal testing is clearly the superior approach.

\section{Acknowledgments}

The HIVNET 024 trial was supported by the HIV Network for Prevention Trials (HIVNET) and sponsored by the U.S. National Institute of Allergy and Infectious Diseases (NIAID), National Institutes of Health (NIH), Department of Health and Human Services, through contracts N01-AI-35173, N01-AI-45200, and N01-AI-35173-117/412. In addition, the trial was supported by the HIV Prevention Trials Network (HPTN) and sponsored by NIAID, the National Institute of Child Health and Human Development, National Institute on Drug Abuse, the National Institute of Mental Health, and the Office of AIDS Research of the National Institutes of Health, U.S. Department of Health and Human Services, through Harvard University (U01-AI-480006), Johns Hopkins University (U01-AI-48005), and the University of Alabama at Birmingham (U01-AI-47972). Support for this work was also provided by the AIDS International Training and Research Program (D43 TW01035-07) and an NIH predoctoral thesis support fellowship (1 F31 HD 046415-01).

The conclusions and opinions expressed in this article are those of the authors and do not necessarily reflect those of the funding agencies and participating institutions.

\section{References}

1. Ament LA, Whalen E. Sexually transmitted diseases in pregnancy: Diagnosis, impact, and intervention. J Obstet Gynecol Neonatal Nurs 1996;25:657-666.

2. Pao D, Goh BT, Bingham JS. Management issues in syphilis. Drugs 2002;62:1447-1461. [PubMed: 12093314]

3. Watson-Jones D, Changulacha J, Gumodoka B, et al. Syphilis in pregnancy in Tanzania. I. Impact of maternal syphilis on outcome of pregnancy. J Infect Dis 2002;186:940-947. [PubMed: 12232834]

4. Finelli L, Berman SM, Koumans EH, et al. Congenital syphilis. Bull World Health Organ 1998;76:126128. [PubMed: 10063689] 
5. Brocklehurst P. Update on the treatment of sexually transmitted infections in pregnancy-1. Int J STD AIDS 1999;10:571-580. [PubMed: 10492423]

6. Genc M, Ledger WJ. Syphilis in pregnancy. Sex Transm Infect 2000;76:73-79. [PubMed: 10858706]

7. Gloyd S, Chai S, Mercer MA. Antenatal syphilis in sub-Saharan Africa: Missed opportunities for mortality reduction. Health Policy Plan 2001;16:29-34. [PubMed: 11238427]

8. Walker DG, Walker GJ. Forgotten but not gone: The continuing scourge of congenital syphilis. Lancet Infect Dis 2002;2:432-436. [PubMed: 12127355]

9. Wendel GD. Gestational and congenital syphilis. Clin Perinatol 1988;15:287-303. [PubMed: 3288424]

10. Cossa HA, Gloyd S, Vaz RG, et al. Syphilis and HIV infection among displaced pregnant women in rural Mozambique. Int J STD AIDS 1994;5:117-123. [PubMed: 8031913]

11. Quinn TC, Cannon RO, Glasser D, et al. The association of syphilis with risk of human immunodeficiency virus infection in patients attending sexually transmitted disease clinics. Arch Intern Med 1990;150:1297-1302. [PubMed: 2353862]

12. Cohen MS. Sexually transmitted diseases enhance HIV transmission: No longer a hypothesis. Lancet 1998;351:5-7. [PubMed: 9652712]

13. Lee MJ, Hallmark RJ, Frenkel LM, et al. Maternal syphilis and vertical perinatal transmission of human immunodeficiency virus type-1 infection. Int J Gynaecol Obstet 1998;63:247-252. [PubMed: 9989893]

14. Gray, G.; McIntyre, J.; Newell, ML. HIV-1 Infection. In: Newell, ML.; McIntyre, J., editors. Congenital and Perinatal Infections: Prevention, Diagnosis and Treatment. Cambridge, MA: Cambridge University Press; 2000. p. 232-257.

15. Wasserheit JN. Epidemiological synergy: Interrelationships between human immunodeficiency virus infection and other sexually transmitted diseases. Sex Transm Dis 1992;19:61-77. [PubMed: 1595015]

16. Fleming DT, Wasserheit JN. From epidemiological synergy to public health policy and practice: The contribution of other sexually transmitted diseases to sexual transmission of HIV infection. Sex Transm Infect 1999;75:3-17. [PubMed: 10448335]

17. HIV Sentinel Surveillance Report. National AIDS Commission and Ministry of Health of The Republic of Malawi; 2003.

18. Ministry of Health Tanzania/National AIDS Control Program (NACP). Surveillance of HIV and Syphilis Infection Among Antenatal Clinic Attendees 2003/2004. 2005 Apr. report

19. Central Statistical Office (Zambia), Central Board of Health (Zambia), and ORC Marco. Zambia Demographic and Health Survey 2001-2002. Calverton, MD: 2002. p. 231

20. Global Prevalence and Incidence of Selected Curable Sexually Transmitted Infections. Geneva: 2001 [Accessed April 13, 2005]. Available at http://www.who.int/docstore/hiv/GRSTI/

21. Kafulafula, G.; Martinson, F.; Msamanga, G.; Sinkala, M. HIVNET 024 Team. Phase III trial of antibiotics to reduce chorioamnionitis-associated MTCT of HIV. XV International AIDS Conference; July 11-16; Bangkok, Thailand. 2004. Program and Abstracts, Abstract ThOrC1418

22. Goldenberg RL, Vermund SH, Goepfert AR, et al. Choriodecidual inflammation: A potentially preventable cause of perinatal HIV-1 transmission. Lancet 1998;352:1927-1930. [PubMed: 9863804]

23. Guay LA, Musoke P, Fleming T, et al. Intrapartum and neonatal singledose nevirapine compared with zidovudine for prevention of mother-to-child transmission of HIV-1 in Kampala, Uganda: HIVNET 012 randomised trial. Lancet 1999;354:795-802. [PubMed: 10485720]

24. Stringer EM, Sinkala M, Stringer JS, et al. Prevention of mother-to-child transmission of HIV in Africa: Successes and challenges in scaling-up a nevirapine-based program in Lusaka, Zambia. AIDS 2003; 17:1377-1382. [PubMed: 12799559]

25. Hoover DR, Munoz A, Carey V, et al. The unseen sample in cohort studies: Estimation of its size and effect. Multicenter AIDS Cohort Study. Stat Med 1991;10:1993-2003. [PubMed: 1805323]

26. Grosskurth H, Mosha F, Todd J, et al. Impact of improved treatment of sexually transmitted diseases on HIV infection in rural Tanzania: Randomised controlled trial. Lancet 1995;346:530-536. [PubMed: 7658778] 
27. Lagarde E, Guyavarch E, Piau JP, et al. Treponemal infection rates, risk factors and pregnancy outcome in a rural area of Senegal. Int J STD AIDS 2003;14:208-215. [PubMed: 12665446]

28. Gertig DM, Kapiga SH, Shao JF, et al. Risk factors for sexually transmitted diseases among women attending family planning clinics in Dar-es-Salaam, Tanzania. Genitourin Med 1997;73:39-43. [PubMed: 9155554]

29. Sombie I, Meda N, Cartoux M, et al. Seroprevalence of syphilis among women attending urban antenatal clinics in Burkina Faso, 1995-8. The DITRAME Study Group. DIminuation de la TRAnsmission Mere-Enfant. Sex Transm Infect 2000;76:314-316. [PubMed: 11026892]

30. Lumbiganon P, Piaggio G, Villar J, et al. The epidemiology of syphilis in pregnancy. Int J STD AIDS 2002;13:486-494. [PubMed: 12171669]

31. How JH, Bowditch JD. Syphilis in pregnancy: Experience from a rural aboriginal community. Aust N Z J Obstet Gynaecol 1994;34:383-389. [PubMed: 7848223]

32. Wilkinson D, Sach M, Connolly C. Epidemiology of syphilis in pregnancy in rural South Africa: Opportunities for control. Trop Med Intern Health 1997;2:57-62.

33. Lago EG, Rodrigues LC, Fiori RM, Stein AT. Congenital syphilis: Identification of two distinct profiles of maternal characteristics associated with risk. Sex Transm Dis 2004;31:33-37. [PubMed: 14695956]

34. Kebede E, Chamiso B. Prevalence of syphilis in pregnancy in Addis Ababa. E Afr Med J 2000;77:212216.

35. Ortashi OM, El Khidir I, Herieka E. Prevalence of HIV, syphilis, Chlamydia trachomatis, Neisseria gonorrhoeae, Trichomonas vaginalis and candidiasis among pregnant women attending an antenatal clinic in Khartoum, Sudan. J Obstet Gynaecol 2004;24:513-515. [PubMed: 15369929]

36. Behets FM, Desormeaux J, Joseph D, et al. Control of sexually transmitted diseases in Haiti: Results and implications of a baseline study among pregnant women living in Cite Soleil Shantytowns. J Infect Dis 1995;172:764-771. [PubMed: 7658070]

37. Bruisten SM. Genital ulcers in women. Curr Womens Health Rep 2003;3:288-298. [PubMed: 12844451]

38. Fitzgerald DW, Behets F, Caliendo A, et al. Economic hardship and sexually transmitted diseases in Haiti's rural Artibonite Valley. Am J Trop Med Hyg 2000;62:496-501. [PubMed: 11220766]

39. Goldenberg RL, Thompson C. The infectious origins of still birth. Am J Obstet Gynecol 2003;189:861-873. [PubMed: 14526331]

40. Urassa WK, Kapiga SH, Msamanga GI, et al. Risk factors for syphilis among HIV-1 infected pregnant women in Dar es Salaam, Tanzania. Afr J Reprod Health 2001;5:54-62. [PubMed: 12471929]

41. Beksinska ME, Mullick S, Kunene B, et al. A case study of antenatal syphilis screening in South Africa: Successes and challenges. Sex Transm Dis 2002;29:32-37. [PubMed: 11773876]

42. Fonck K, Kidula N, Kirui P, et al. Pattern of sexually transmitted diseases and risk factors among women attending an STD referral clinic in Nairobi, Kenya. Sex Transm Dis 2000;27:417-423. [PubMed: 10949433]

43. Kambarami RA, Manyame B, Macq J. Syphilis in Murewa District, Zimbabwe: An old problem that rages on. Cent Afr J Med 1998;44:229-232. [PubMed: 10101428]

44. Hook EW III, Peeling RW. Syphilis control—A continuing challenge. N Engl J Med 2004;351:122124. [PubMed: 15247352]

45. Goldenberg RL, Stringer JS, Sinkala M, et al. Perinatal HIV transmission: Developing country considerations. J Matern Fetal Neonatal Med 2002;12:149-158. [PubMed: 12530611]

46. Grosskurth H, Gray R, Hayes R, et al. Control of sexually transmitted diseases for HIV-1 prevention: Understanding the implications of the Mwanza and Rakai trials. Lancet 2000;355:1981-1987. [PubMed: 10859054]

47. UNAIDS. Country HIV and AIDS estimates, end 2003. 2005 [Accessed June 3]. p. 50Available at http://www.unaids.org/en/geographical+area/by+country/malawi.asp; http://www.unaids.org/en/geographical+area/by+country/united+republic+of+tanzania.asp; http://www.unaids.org/en/geographical+area/+by+country/zambia.asp

48. Peeling RW, Mabey D, Fitzgerald DW, et al. Avoiding HIV and dying of syphilis. Lancet 2004;364:1561-1563. [PubMed: 15519615] 
49. Reid SE, Reid CA, Vermund SH. Antiretroviral therapy in sub-Saharan Africa: Adherence lessons from tuberculosis and leprosy. Int J STD AIDS 2004;15:713-716. [PubMed: 15537453]

50. Soto, MA.; Almario, DA.; McCormick, MC., editors. Reducing the Odds Preventing Perinatal Transmission of HIV in the United States. Washington, DC: National Academy Press; 1998. Committee on Perinatal Transmission of HIV, Report of the Institute of Medicine.

51. Taha TE, Dallabetta GA, Hoover DR, et al. Trends of HIV-1 and sexually transmitted diseases among pregnant and postpartum women in urban Malawi. AIDS 1998;12:197-203. [PubMed: 9468369] 
TABLE 1

Confirmed Syphilis-Seropositive and Baseline Sociodemographic and Sexual/Obstetric History Characteristics Among 2636 Enrolled Antenatal Attendees in the HIVNET 024 Clinical Trial in Sub-Saharan Africa

\begin{tabular}{|c|c|c|}
\hline Characteristic & $\begin{array}{l}\text { Women } \\
\mathbf{n}(\%)\end{array}$ & $\begin{array}{l}\text { Percent Confirmed } \\
\text { Syphilis-Seropositive } \\
\text { and } P \text { Value }\end{array}$ \\
\hline Site & $\mathrm{n}=2,636$ & \\
\hline Blantyre, Malawi & 559 (21.2) & 6.3 \\
\hline Lilongwe, Malawi & $896(34.0)$ & 5.1 \\
\hline Dar es Salaam, Tanzania & $428(16.2)$ & 1.4 \\
\hline \multirow[t]{2}{*}{ Lusaka, Zambia } & 753 (28.6) & 11.7 \\
\hline & & $P<0.0001$ \\
\hline HIV serostatus & $\mathrm{n}=2,636$ & \\
\hline Positive & $2,270(86.1)$ & 7.3 \\
\hline \multirow[t]{2}{*}{ Negative } & $366(13.9)$ & 2.5 \\
\hline & & $P=0.0005$ \\
\hline Age in years & $\mathrm{n}=2,636$ & \\
\hline $16-19$ & $322(12.2)$ & 3.7 \\
\hline $20-24$ & $1,013(38.4)$ & 9.1 \\
\hline $25-29$ & $845(32.1)$ & 5.3 \\
\hline \multirow[t]{2}{*}{$30-45$} & $456(17.3)$ & 5.7 \\
\hline & & $P=0.0007$ \\
\hline $\begin{array}{l}\text { Years of formal education } \\
\text { (completed years) }\end{array}$ & $\mathrm{n}=2,635$ & \\
\hline None & $233(8.8)$ & 10.3 \\
\hline $1-5$ & $614(23.3)$ & 8.5 \\
\hline \multirow[t]{2}{*}{$6-18$} & $1,788(67.9)$ & 5.5 \\
\hline & & $P=0.002$ \\
\hline Literate (self-reported) & $\mathrm{n}=2,636$ & \\
\hline Yes & $2,051(77.8)$ & 5.3 \\
\hline \multirow[t]{2}{*}{ No } & $585(22.2)$ & 11.3 \\
\hline & & $P \leq 0.0001$ \\
\hline Marital status & $\mathrm{n}=2,636$ & \\
\hline $\begin{array}{l}\text { Married and/or living with } \\
\text { partner (referent) }\end{array}$ & $2,431(92.2)$ & 6.3 \\
\hline $\begin{array}{l}\text { Never married or living } \\
\text { with partner }\end{array}$ & $141(5.4)$ & 4.3 \\
\hline \multirow{2}{*}{$\begin{array}{l}\text { Divorced, separated, or } \\
\text { widowed }\end{array}$} & $64(2.4)$ & 23.4 \\
\hline & & $P \leq 0.0001$ \\
\hline Electricity on premises & $\mathrm{n}=2,636$ & \\
\hline Yes & $1,048(39.8)$ & 5.1 \\
\hline \multirow[t]{2}{*}{ No } & $1,588(60.2)$ & 7.7 \\
\hline & & $P=0.008$ \\
\hline $\begin{array}{l}\text { Running water on } \\
\text { premises }\end{array}$ & $\mathrm{n}=2,636$ & \\
\hline Yes & $1,084(41.1)$ & 5.3 \\
\hline
\end{tabular}




\begin{tabular}{|c|c|c|}
\hline Characteristic & $\begin{array}{l}\text { Women } \\
\text { n }(\%)\end{array}$ & $\begin{array}{l}\text { Percent Confirmed } \\
\text { Syphilis-Seropositive } \\
\text { and } P \text { Value }\end{array}$ \\
\hline \multirow[t]{2}{*}{ No } & $1,552(58.9)$ & 7.6 \\
\hline & & $P=0.02$ \\
\hline Cook with paraffin stove & $\mathrm{n}=2,636$ & \\
\hline Yes & $470(17.8)$ & 2.3 \\
\hline \multirow[t]{2}{*}{ No } & $2,166(82.2)$ & 7.6 \\
\hline & & $P \leq 0.0001$ \\
\hline $\begin{array}{l}\text { Number of lifetime sexual } \\
\text { partners including } \\
\text { spouse or partner }\end{array}$ & $\mathrm{n}=2,617$ & \\
\hline 1 & $628(24.0)$ & 4.6 \\
\hline 2 & $848(32.4)$ & 5.7 \\
\hline \multirow[t]{2}{*}{$3-25$} & $1,141(43.6)$ & 8.5 \\
\hline & & $P<0.003$ \\
\hline $\begin{array}{l}\text { In the last year, treated for } \\
\text { genital ulcers }\end{array}$ & $\mathrm{n}=2,633$ & \\
\hline Yes & $93(3.5)$ & 21.5 \\
\hline \multirow[t]{2}{*}{ No } & $2,540(96.5)$ & 6.1 \\
\hline & & $P \leq 0.0001$ \\
\hline $\begin{array}{l}\text { Number of pregnancies, } \\
\text { including current }\end{array}$ & $\mathrm{n}=2,636$ & \\
\hline 1 & $501(19.0)$ & 4 \\
\hline $2-4$ & $1,712(65.0)$ & 7.3 \\
\hline \multirow[t]{2}{*}{$5-12$} & $423(16.1)$ & 7.1 \\
\hline & & $P=0.03$ \\
\hline Number of stillbirths & $\mathrm{n}=2,636$ & \\
\hline 0 & $2,425(92)$ & 5.7 \\
\hline 1 & $180(6.8)$ & 15.6 \\
\hline \multirow[t]{2}{*}{$2-5$} & $31(1.2)$ & 25.8 \\
\hline & & $P \leq 0.0001$ \\
\hline $\begin{array}{l}\text { Number of children born } \\
>3 \text { wk early }\end{array}$ & $\mathrm{n}=2,636$ & \\
\hline 0 & $2,509(95.2)$ & 6.2 \\
\hline 1 & $95(3.6)$ & 16.8 \\
\hline \multirow[t]{2}{*}{$2-8$} & $32(1.2)$ & 9.4 \\
\hline & & $P=0.002$ \\
\hline
\end{tabular}


TABLE 2

Results of Multivariable Analysis: Risk Factors for Syphilis (RPR or VDRL + with confirmation by TPHA, MHA-TP, or TPPA)

\begin{tabular}{|c|c|c|c|}
\hline \multirow[b]{2}{*}{ Characteristic } & \multicolumn{2}{|c|}{ Crude Adjusted } & \multirow[b]{2}{*}{$P$ Value } \\
\hline & Odds Ratio & $\begin{array}{l}\text { Odds Ratio } \\
\text { (95\% confidence } \\
\text { interval) }\end{array}$ & \\
\hline \multicolumn{4}{|l|}{ Site } \\
\hline Dar es Salaam, Tanzania (referent) & 1.0 & 1.0 & \\
\hline Blantyre, Malawi & 4.7 & $4.5(1.4-14.4)$ & 0.01 \\
\hline Lilongwe, Malawi & 3.8 & $3.2(1.0-10.0)$ & 0.04 \\
\hline Lusaka, Zambia & 9.3 & $9.0(2.9-28.2)$ & 0.0002 \\
\hline \multicolumn{4}{|l|}{ HIV infection status } \\
\hline Seronegative (referent) & 1.0 & 1.0 & \\
\hline Seropositive & 3.1 & $3.3(1.6-6.9)$ & 0.002 \\
\hline \multicolumn{4}{|l|}{ Age (years) } \\
\hline $16-19$ (referent) & 1.0 & 1.0 & \\
\hline $20-24$ & 2.6 & $2.5(1.3-5.0)$ & 0.01 \\
\hline $25-29$ & 1.5 & $1.2(0.6-2.6)$ & 0.6 \\
\hline $30-45$ & 1.6 & $1.4(0.6-3.2)$ & 0.4 \\
\hline \multicolumn{4}{|l|}{ Formal education (completed years) } \\
\hline 0 (referent) & 1.0 & 1.0 & \\
\hline $1-5$ & 0.8 & $0.9(0.5-1.5)$ & 0.6 \\
\hline $6-18$ & 0.5 & $0.7(0.4-1.5)$ & 0.4 \\
\hline \multicolumn{4}{|l|}{ Literacy (self-reported) } \\
\hline Not able to read (referent) & 1.0 & 1.0 & \\
\hline Able to read & 0.4 & $0.7(0.4-1.2)$ & 0.2 \\
\hline \multicolumn{4}{|l|}{ Marital status } \\
\hline Married/living with partner (referent) & 1.0 & 1.0 & \\
\hline Never married/not living with partner & 0.7 & $0.8(0.3-2.0)$ & 0.7 \\
\hline Divorced/separated/widowed & 4.5 & $2.9(1.5-5.7)$ & 0.001 \\
\hline \multicolumn{4}{|l|}{ Presence of utilities on premises } \\
\hline No electricity (referent) & 1.0 & 1.0 & \\
\hline Electricity on premises & 0.6 & $0.9(0.6-1.3)$ & 0.5 \\
\hline No running water on premises (referent) & 1.0 & 1.0 & \\
\hline Running water on premises & 0.7 & $0.9(0.6-1.3)$ & 0.6 \\
\hline \multicolumn{4}{|l|}{ Method used for daily cooking } \\
\hline No paraffin stove (referent) & 1.0 & 1.0 & \\
\hline Paraffin stove & 0.3 & $1.1(0.5-2.6)$ & 0.8 \\
\hline \multicolumn{4}{|c|}{ Number of lifetime sexual partners including spouse } \\
\hline 1 (referent) & 1.0 & 1.0 & \\
\hline 2 & 1.2 & $1.1(0.7-1.9)$ & 0.6 \\
\hline $3-25$ & 1.9 & $1.5(1.0-2.4)$ & 0.1 \\
\hline
\end{tabular}




\begin{tabular}{|c|c|c|c|}
\hline \multirow[b]{2}{*}{ Characteristic } & \multicolumn{2}{|c|}{ Crude Adjusted } & \multirow[b]{2}{*}{$P$ Value } \\
\hline & Odds Ratio & $\begin{array}{l}\text { Odds Ratio } \\
\text { (95\% confidence } \\
\text { interval) }\end{array}$ & \\
\hline Not treated for genital ulcers (referent) & 1.0 & 1.0 & \\
\hline Treated for genital ulcers & 4.2 & $2.9(1.6-5.3)$ & 0.0003 \\
\hline \multicolumn{4}{|c|}{ Number of pregnancies, including this pregnancy } \\
\hline 1 (referent) & 1.0 & 1.0 & \\
\hline $2-4$ & 1.9 & $1.5(0.8-2.5)$ & 0.2 \\
\hline $5-12$ & 1.8 & $1.2(0.6-2.7)$ & 0.6 \\
\hline \multicolumn{4}{|l|}{ Number of stillbirths } \\
\hline 0 (referent) & 1.0 & 1.0 & \\
\hline 1 & 3.0 & $2.8(1.7-4.5)$ & $<0.0001$ \\
\hline $2-5$ & 5.7 & $4.3(1.7-11.2)$ & 0.002 \\
\hline \multicolumn{4}{|l|}{ Number of children born $>3$ wk early } \\
\hline 0 (referent) & 1.0 & 1.0 & \\
\hline 1 & 3.1 & $2.7(1.5-5.0)$ & 0.002 \\
\hline $2-8$ & 1.6 & $1.5(0.4-5.4)$ & 0.5 \\
\hline
\end{tabular}

RPR indicates rapid plasma reagin assay; VDRL = venereal diseases reference laboratory tests; TPHA = treponema pallidum hemagglutination assay; MHA-TP $=$ microhemagglutination $T$. pallidum test TPPA $=T$. pallidum particle agglutination test. 